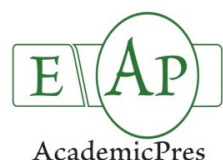

AcademicPres

\title{
Genetic Diversity and Relationships in Local Varieties of Eggplant from Different Cultivar Groups as Assessed by Genomic SSR Markers
}

\author{
Santiago VILANOVA, Maria HURTADO, Adriana CARDONA, Mariola PLAZAS, \\ Pietro GRAMAZIO, Francisco J. HERRAIZ, Isabel ANDÚJAR, Jaime PROHENS*
}

\author{
Instituto de Conservación y Mejora de la Agrodiversidad Valenciana, Universitat Politécnica de València, Camino de Vera 14, \\ 46022 Valencia, Spain; jprohens@btc.upv.es (*corresponding author)
}

\begin{abstract}
Spain is a secondary center of diversity for eggplant (Solanum melongena). Spanish landraces of eggplant are normally classified in four cultivar groups: Round, Listada de Gandía, Semi-Long, and Long. We have used 19 genomic SSRs for the molecular characterization of 30 eggplant accessions corresponding to the four cultivar groups. Sixteen SSRs of which 15 were polymorphic could be amplified and 65 polymorphic alleles, with a range of two to 11 alleles/locus, were detected. The polymorphism information content $(P I C)$ of SSR markers ranged from 0.07 to 0.77 , with an average value of $P I C=0.50$. The mean observed heterozygosity $\left(H_{o}\right)$ presented a very low value $H_{o}=0.01$, while the mean expected heterozygosity $\left(H_{e}\right)$ had a value of $H_{e}=0.57$. Multivariate cluster analyses revealed that a considerable diversity exists within each of the cultivar groups. Listada de Gandía and Long cultivar groups were clearly separated from each other in different branches of phenogram. The principal coordinates analysis $(\mathrm{PCoA})$ confirmed that each of the cultivar groups is genetically diverse and, with the exception of the Round group, they plot in different areas of the PCoA graph. Overall, the results indicate that Spanish eggplant landraces present a high degree of homozygosis, considerable intra-cultivar group diversity, and a certain degree of genetic differentiation. This information is of interest for selection and breeding of eggplant as well as for germplasm conservation.
\end{abstract}

Keywords: forage, breeding, cultivar groups, fruit shape, landraces, multivariate analysis, Solanum melongena

\section{Introduction}

Eggplant (Solanum melongena L.) was domesticated in Southeast Asia (Meyer et al. 2012). From there it spread to other tropical and subtropical areas of the world, where selection and other microevolutive forces led to the development of a wide array of locally adapted landraces of eggplant and to the emergence of secondary centers of diversity (Cericola et al., 2013; Hurtado et al., 2012; Prohens et al., 2005; Tümbilen et al., 2011). Differentiation between eggplants of Southeast Asia on one side and those of the Middle East, Africa and Mediterranean region of Europe on the other have led to the recognition of two major groups of eggplant cultivar groups denominated, respectively, Oriental and Occidental eggplants (Cericola $e t$ al., 2013; Vilanova et al., 2012).

The Mediterranean region of Spain is considered as a secondary center of diversity (Hurtado et al., 2012; Prohens et al., 2005) in which four cultivar groups are normally recognized: Round, Listada de Gandía, Semi-Long, and Long (Hurtado et al., 2013; Muñoz-Falcón et al., 2011; Prohens et al., 2005). These four cultivar groups are distinguished mostly by the fruit length/width ratio (i.e., the
Round, Semi-Long, and Long cultivar groups) (Cericola $e t$ al., 2013; Hurtado et al., 2013; Prohens et al., 2005; Tümbilen et al., 2011), and also for the presence of purple stripes on a white background combined with a fruit shape intermediate between the Round and Semi-Long types in the case of Listada de Gandía (Hurtado et al., 2013; MuñozFalcón et al., 2011).

Development of new eggplant varieties addressing old and new breeding objectives (Barchi et al., 2012; Lebeau et al., 2013; Sunseri et al., 2003) requires of genetic diversity. Normally development of new commercial varieties, is based on intra-varietal group crossings, except in the case of the Semi-Long type, which can also be obtained by crossings between Round and Long types. Increasing the genetic base of new eggplant cultivars can be achieved through the incorporation of local landraces in the commercial breeding programmes (Muñoz-Falcón et al., 2009a). Therefore, the study of genetic diversity and relationships of collections of local varieties provides information of relevance for the breeding programmes.

Several molecular studies (Cericola et al., 2013; Prohens et al., 2005; Tümbilen et al., 2011) have shown that eggplant cultivar groups are genetically diverse. In the case of 
Spanish varieties, Prohens et al. (2005) studied the AFLP diversity in a collection of eggplants from the Round, Listada de Gandía, Semi-Long, and Long types and found considerable intra-group diversity and genetic differentiation among groups. However, SSRs have proved as more powerful than AFLPs to study the relationships amongst closely related eggplant materials (Muñoz-Falcón et al., 2009b). Furthermore, unlike AFLPs, which are dominant, SSRs are co-dominant, which allows determining the levels of observed heterozygosity. In particular, in eggplant, genomic SSRs have proved as much more informative than EST-SSRs (Muñoz-Falcón et al., 2011). Therefore, in order to obtain information of interest for eggplant breeding and germplasm conservation, we studied the diversity, heterozygosity and relationships of 30 eggplant varieties from the Region of Valencia, situated in the Mediterranean region of Spain using genomic SSR markers.

\section{Materials and methods}

\section{Plant material and DNA extraction}

A total of 30 accessions corresponding to four cultivar groups (Round, Listada de Gandía, Semi-Long, and Long) were used (Tab. 1). All the accessions used, except the commercial selection Listada Clemente (Semillas Clemente, Vitoria, Spain), and the breeding line LF3-24 (INRA, France) are local landraces from the region of Valencia (Spain). A number of these accessions have been recently characterized by fruit shape (Hurtado et al., 2013), and phenolics content (Plazas et al., 2013).

For each accession, genomic DNA was extracted from $75 \mathrm{mg}$ of young leaf tissue using the CTAB method (Doyle and Doyle, 1987). DNA concentration was quantified, after electrophoresis on a $1.0 \%$ agarose gel, using a Nanodrop ND-1000 (Nanodrop Technologies, Wilminton, Delaware, USA) spectrophotometer. Samples were adjusted to a DNA concentration of $20 \mathrm{ng} / \mu \mathrm{l}$. The quality of DNA was evaluated through the $260 / 280 \mathrm{~nm}$ and $260 / 230 \mathrm{~nm}$ absorbance ratios (Sambrook et al., 1989).

\section{Molecular characterization}

Nineteen genomic highly polymorphic SSR markers developed by Vilanova et al. (2012) were used to screen the 30 eggplant accessions (Tab. 2). SSRs were tested following the M13-tail PCR method of Schuelke et al. (2000) to facilitate the incorporation of a dye label during the PCR. An M13-tailed forward primer was used in combination with a standard M13 primer dye-labeled with FAM, NED, PET, or VIC fluorophores at its 5 '-end.

PCR amplifications were performed in a total volume of $12 \mu \mathrm{l}$ with $20 \mathrm{ng}$ of DNA, $1.5 \mathrm{mM} \mathrm{MgCl}, 0.05 \mu \mathrm{M}$ of forward primer, $0.25 \mu \mathrm{M}$ of reverse primer, $0.2 \mu \mathrm{M}$ of fluorescent M-13 primer, $0.2 \mathrm{mM}$ dNTPs, and 0.04 units of Taq DNA polymerase. Amplifications were carried out in an Eppendorf Mastercycler ep gradient S (Eppendorf AG, Hamburg, Germany) thermocycler. Two different protocols for amplification (T or TD) were used depending on the marker (Tab. 2). The $\mathrm{T}$ protocol consisted in an initial step at $94^{\circ} \mathrm{C}$ for $5 \mathrm{~min}, 35$ cycles of $94^{\circ} \mathrm{C}$ for $30 \mathrm{~s}, 1$ $\min$ at the appropriated annealing temperature (Tab. 2), 72 ${ }^{\circ} \mathrm{C}$ for $2 \mathrm{~min}$, and final $10 \mathrm{~min}$ extension at $72{ }^{\circ} \mathrm{C}$. The TD protocol consisted in an initial step at $94^{\circ} \mathrm{C}$ for 2 min, 7 cycles of $94^{\circ} \mathrm{C}$ for $15 \mathrm{~s}, 55-48^{\circ} \mathrm{C}$ (beginning with $55^{\circ} \mathrm{C}$ in the first cycle and reducing $1{ }^{\circ} \mathrm{C}$ in each of the subsequent cycles) for $30 \mathrm{~s}, 72^{\circ} \mathrm{C}$ for $45 \mathrm{~s}$, and final $10 \mathrm{~min}$ extension at $72^{\circ} \mathrm{C}$; subsequently, other 28 cycles are performed with the following conditions: $94^{\circ} \mathrm{C}$ for $15 \mathrm{~s}, 48^{\circ} \mathrm{C}$ for $30 \mathrm{~s}, 72^{\circ} \mathrm{C}$ for $45 \mathrm{~s}$, and final $10 \mathrm{~min}$ extension at $72^{\circ} \mathrm{C}$.

PCR products were separated on an ABI Prism 3100 Avant (Applied Biosystems, Foster City, California, USA) genetic analyzer using GeneScan 3.7 (Applied Biosystems)

Tab. 1. Accessions used in the present work, fruit weight and fruit length/width ratio (mean $\pm \mathrm{SE}$ ), grouped according to their varietal group

\begin{tabular}{|c|c|c|c|}
\hline Accession $^{a}$ & Code & Fruit weight & $\begin{array}{c}\text { Fruit length / } \\
\text { width ratio }\end{array}$ \\
\hline \multicolumn{4}{|c|}{ Round } \\
\hline B-31 & B31 & $225 \pm 17$ & $1.09 \pm 0.05$ \\
\hline B-32 & B32 & $346 \pm 33$ & $1.63 \pm 0.05$ \\
\hline V-S-9 & VS9 & $233 \pm 18$ & $0.83 \pm 0.02$ \\
\hline V-S-13 & VS13 & $180 \pm 12$ & $0.97 \pm 0.03$ \\
\hline \multicolumn{4}{|c|}{ Listada de Gandía } \\
\hline $07-A 25-01$ & $07 \mathrm{~A}$ & $330 \pm 26$ & $2.31 \pm 0.08$ \\
\hline IVIA-025 & I025 & $330 \pm 16$ & $1.70 \pm 0.06$ \\
\hline IVIA-347 & I347 & $300 \pm 26$ & $1.35 \pm 0.06$ \\
\hline Listada Clemente & $\mathrm{LC}$ & $209 \pm 23$ & $2.47 \pm 0.07$ \\
\hline V-S-1 & VS1 & $239 \pm 32$ & $1.59 \pm 0.07$ \\
\hline V-S-2 & VS2 & $278 \pm 15$ & $1.60 \pm 0.05$ \\
\hline V-S-7 & VS7 & $346 \pm 20$ & $1.47 \pm 0.06$ \\
\hline V-S-8 & VS8 & $288 \pm 24$ & $2.36 \pm 0.10$ \\
\hline V-S-10 & VS10 & $169 \pm 12$ & $1.56 \pm 0.07$ \\
\hline V-S-11 & VS11 & $182 \pm 9$ & $1.87 \pm 0.05$ \\
\hline V-S-15 & VS15 & $228 \pm 12$ & $1.86 \pm 0.03$ \\
\hline \multicolumn{4}{|c|}{ Semi-long } \\
\hline B-33 & B33 & $171 \pm 8$ & $2.93 \pm 0.07$ \\
\hline B-36 & B36 & $176 \pm 16$ & $2.99 \pm 0.12$ \\
\hline V-S-14 & VS14 & $250 \pm 16$ & $2.88 \pm 0.09$ \\
\hline V-S-16 & VS16 & $290 \pm 19$ & $2.61 \pm 0.35$ \\
\hline V-S-17 & VS17 & $228 \pm 20$ & $2.99 \pm 0.12$ \\
\hline V-S-18 & VS18 & $168 \pm 14$ & $3.47 \pm 0.11$ \\
\hline \multicolumn{4}{|c|}{ Long } \\
\hline B-35 & B35 & $218 \pm 15$ & $3.98 \pm 0.22$ \\
\hline LF3-24 & LF3 & $181 \pm 13$ & $3.99 \pm 0.12$ \\
\hline V-S-3 & VS3 & $164 \pm 12$ & $3.92 \pm 0.13$ \\
\hline V-S-4 & VS4 & $206 \pm 18$ & $3.84 \pm 0.14$ \\
\hline V-S-5 & VS5 & $232 \pm 19$ & $4.43 \pm 0.13$ \\
\hline V-S-6 & VS6 & $223 \pm 13$ & $4.02 \pm 0.13$ \\
\hline V-S-12 & VS12 & $200 \pm 12$ & $5.36 \pm 0.11$ \\
\hline V-S-19 & VS19 & $252 \pm 15$ & $4.52 \pm 0.11$ \\
\hline V-S-21 & VS21 & $301 \pm 24$ & $3.88 \pm 0.23$ \\
\hline
\end{tabular}

${ }^{a}$ All accessions are local landraces of the Region of Valencia (Spain), except Listada Clemente, which is a commercial selection (Semillas Clemente, Vitoria, Spain) of the Listada de Gandía type, and LF3-24, which is a breeding line from INRA (France). 
61

Tab. 2. SSR markers used in the present study along with their repeat motif, amplification protocol, annealing temperature, and linkage group in which they map (Vilanova et al., 2010, 2012)

\begin{tabular}{ccccc}
\hline SSR locus & Repeat motif & Protocol $^{\mathbf{a}}$ & Annealing temperature & Linkage group $^{-}$ \\
\hline CSM4 & $(\mathrm{GA})_{15}$ & TD & $55-48$ & Unknown \\
CSM7 & $(\mathrm{CT})_{10}$ & $\mathrm{TD}$ & $55-48$ & 6 \\
CSM12 & $(\mathrm{AG})_{12}$ & $\mathrm{~T}$ & 51 & 3 \\
CSM27 & $(\mathrm{GA})_{23}$ & $\mathrm{~T}$ & $55-48$ & 12 \\
CSM29 & $(\mathrm{AG})_{17}$ & $\mathrm{TD}$ & 51 & 9 \\
CSM30 & $(\mathrm{CT})_{20}$ & $\mathrm{~T}$ & 51 & 1 \\
CSM31 & $(\mathrm{AG})_{28}$ & $\mathrm{~T}$ & 51 & 4 \\
CSM32 & $(\mathrm{AG})_{23}$ & $\mathrm{~T}$ & 51 & 9 \\
CSM36 & $(\mathrm{GA})_{27}$ & $\mathrm{~T}$ & 51 & 4 \\
CSM40 & $(\mathrm{CT})_{45}$ & $\mathrm{~T}$ & $55-48$ & 1 \\
CSM43 & $(\mathrm{AG})_{14}$ & $\mathrm{TD}$ & $55-48$ & 3 \\
CSM44 & $(\mathrm{AG})_{14}$ & $\mathrm{~T}$ & 50 & 5 \\
CSM45 & $(\mathrm{AG})_{16}$ & $\mathrm{TD}$ & 51 & Unknown \\
CSM52 & $(\mathrm{TC})_{12}$ & $\mathrm{~T}$ & 51 & 9 \\
CSM54 & $(\mathrm{GA})_{19}$ & $\mathrm{~T}$ & 51 & Unknown \\
CSM57 & $(\mathrm{CT})_{8}$ & $\mathrm{~T}$ & $55-48$ & Unknown \\
CSM62 & $(\mathrm{GA})_{27}$ & $\mathrm{TD}$ & $55-48$ & 12 \\
CSM74 & $(\mathrm{GA})_{26}$ & $\mathrm{TD}$ & & 10 \\
CSM78 & $(\mathrm{CT})_{19}$ & & & \\
\hline
\end{tabular}

${ }^{\text {a }}$ See text for technical details of the amplification protocols

software. SSR alleles were precisely sized using GeneScan between two (CSM52) and 11 (CSM31) alleles (Tab. 3).

$500 \mathrm{Liz}$ (Applied Biosystems) molecular size standards with Genotyper 3.7 software (Applied Biosystems).

\section{Data analysis}

For each SSR locus, the number of polymorphic alleles $\left(N_{a}\right)$, frequency of the predominant allele $(f)$, and effective number of alleles $\left(N_{e}\right)$ was determined using the PowerMaker software (Liu and Muse, 2005).

The polymorphism information content $(P I C)$ was calculated as PIC $=1-\sum_{i=1}^{n} p_{i}^{2}-\sum_{i=i+1}^{n} 2 p_{i}^{2} p_{i}^{2}$, where $n$ is the total number of alleles detected, $p_{i}$ is the frequency of the $i$ th allele, and $p_{j}$ is the frequency of the $j$ th allele (Botstein $e t$ al., 1980). Also, the observed heterozygosity $\left(H_{o}\right)$, expected heterozygosity $\left(H_{e}\right)$, calculated as $H e=1-\sum_{i=1}^{n} p_{i}^{2}$, were determined. Nei and Li (1979) genetic similarities were calculated and a neighbor-joining phenogram was built using genetic distances with the PowerMaker software (Liu and Muse, 2005) and plotted using TreeView software (Page, 1996). Genetic distances were also used to graphically represent genetic relationships among accessions by principal coordinates analysis (PCoA) using GenAlEx 6.5 software (Peakall and Smouse, 2012).

\section{Results and discussion}

\section{SSR characterization and diversity}

The 19 SSR markers could be amplified, but for three of them (CSM36, CSM44, and CSM78) the PCR products could not be successfully resolved. The 16 remaining SSR markers were polymorphic with the exception of CSM32, for which only one allele was detected. A total of 65 alleles were detected for the 15 polymorphic SSR loci, with an average number of alleles/locus $\left(N_{a}\right)$ of 4.33 and a range

The frequency of the predominant allele $\left(f_{p}\right)$ ranged between 0.36 (CSM31) and 0.97 (CSM74), although with the exception of the latter SSR locus (CSM74) in all cases the $f_{p}$ values have been below 0.65 (Tab. 3). The effective number of alleles $\left(N_{e}\right)$ ranged between 1.07 (CSM74) and 4.85 (CSM31), and with the exception of CSM74 and

Tab. 3. SSR polymorphic markers, number of alleles per locus $\left(N_{a}\right)$, frequency of the predominant allele $(f)$, number of effective alleles per locus $\left(N_{e}\right)$, polymorphism information content $(P I C)$, observed heterozygosity $\left(H_{o}\right)$, and expected heterozygosity $\left(H_{e}\right)$ in the studied collection of 30 eggplant accessions

\begin{tabular}{ccccccc}
\hline $\begin{array}{c}\text { SSR } \\
\text { locus }\end{array}$ & $N_{a}$ & $f$ & $N_{e}$ & $P I C$ & $H_{o}$ & $H_{e}$ \\
\hline CSM4 & 6 & 0.43 & 3.03 & 0.61 & 0.04 & 0.67 \\
CSM7 & 3 & 0.55 & 2.21 & 0.46 & 0.00 & 0.55 \\
\hline CSM12 & 3 & 0.50 & 2.14 & 0.42 & 0.00 & 0.53 \\
CSM27 & 4 & 0.57 & 2.47 & 0.54 & 0.00 & 0.59 \\
CSM29 & 3 & 0.56 & 2.31 & 0.49 & 0.00 & 0.57 \\
CSM30 & 3 & 0.54 & 2.12 & 0.42 & 0.00 & 0.53 \\
\hline CSM31 & 11 & 0.36 & 4.85 & 0.77 & 0.00 & 0.79 \\
CSM40 & 6 & 0.39 & 3.32 & 0.65 & 0.00 & 0.70 \\
CSM43 & 3 & 0.59 & 2.04 & 0.41 & 0.00 & 0.51 \\
CSM45 & 3 & 0.52 & 2.14 & 0.42 & 0.00 & 0.53 \\
\hline CSM52 & 2 & 0.58 & 1.95 & 0.37 & 0.00 & 0.49 \\
CSM54 & 5 & 0.37 & 3.74 & 0.69 & 0.00 & 0.73 \\
\hline CSM57 & 5 & 0.63 & 2.025 & 0.52 & 0.04 & 0.55 \\
CSM62 & 6 & 0.38 & 3.38 & 0.65 & 0.00 & 0.70 \\
\hline CSM74 & 2 & 0.97 & 1.07 & 0.06 & 0.00 & 0.06 \\
Mean & 4.33 & 0.53 & 2.60 & 0.50 & 0.01 & 0.57 \\
\hline
\end{tabular}


CSM52, which are the only polymorphic markers with $N_{a}=2$ (and therefore $N_{e}<2$ ), all loci had $N_{e}>2$ (Tab. 3).

The average value for the $P I C$ value of the SSR markers tested was of 0.50 , but the $P I C$ value of individual SSR markers ranged between 0.07 (CSM74) and 0.77 (CSM31) (Tab. 3). The mean value for the observed heterozygosity $\left(H_{o}\right)$ was very low $\left(H_{0}=0.01\right)$, corresponding to $H_{o}=0.00$ values for 13 out of the 15 polymorphic SSR loci and to low values $\left(H_{0}=0.04\right)$ for the two remaining loci (CSM4 and CSM57). Conversely, the mean value for the expected heterozygosity $\left(H_{e}\right)$ was much higher $\left(H_{e}=0.57\right)$, with values for individual SSR loci ranging from 0.06 (CSM74) to 0.79 (CSM31).

\section{Multivariate analyses}

The cluster analysis performed showed that the four cultivar groups present a considerable diversity (Fig. 1). However, a clear separation of the Long and Listada de Gandía accessions in different basal branches of the phenogram was observed (Fig. 1). All the Listada de Gandía accessions, except accession VS11, are clustered together in one of the sub-branches of the phenogram. Also, all Long accessions, except B35, are clustered together in another sub-branch in which there are also a Round (B32) and a Semi-Long (B33) accessions. Semi-Long, and particularly, the Round accessions, do not present this pattern of clustering, and are scattered in different branches of the phenogram.

When considering the principal coordinates analysis (PCoA), the first and second principal coordinates account, respectively, for $47 \%$ and $13 \%$ of the total variation. The representation of accessions in the PCoA graph shows that the cultivar groups are diverse, although each of them plot in different parts of the graph (Fig. 2).

In this respect, all Listada de Gandía accessions present positive values of the first coordinate and either low positive or negative values of the second coordinate and plot together, not being intermingled with other cultivar groups. Only the odd VS11 accession plots closer to a Round accession (VS9) than to the other Listada de Gandía accessions. All Long accessions present negative values for the first coordinate and either low positive or negative values for the second coordinate (Fig. 2).

Also, all Semi-Long accessions plot in the same area of

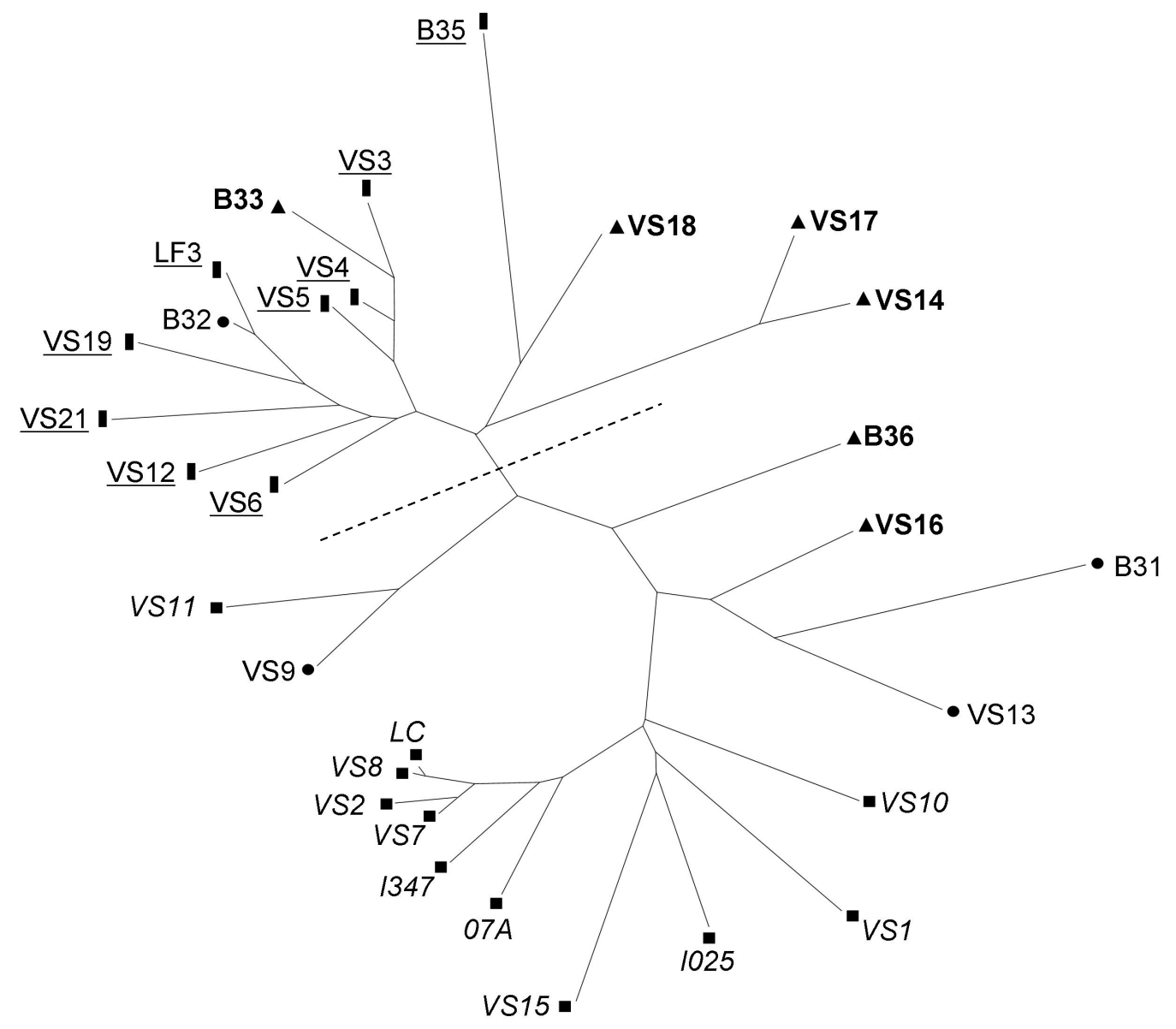

Fig. 1. Unrooted neighbor-joining phenogram of 30 eggplant accessions based on 15 polymorphic SSR markers. Phenetic relationships were derived from genetic distances ( $\mathrm{Nei}$ and $\mathrm{Li}, 1979$ ). The different groups of accessions are represented by different symbols and font types: Round ( $\bullet$ and normal font); Listada de Gandía ( $\bullet$ and italics font); Semi-long ( $\boldsymbol{\Delta}$ and bold font); Long (】 and underlined font). The dashed line separates the phenogram branches that contain all Long accessions (above) and all the Listada de Gandía accessions 


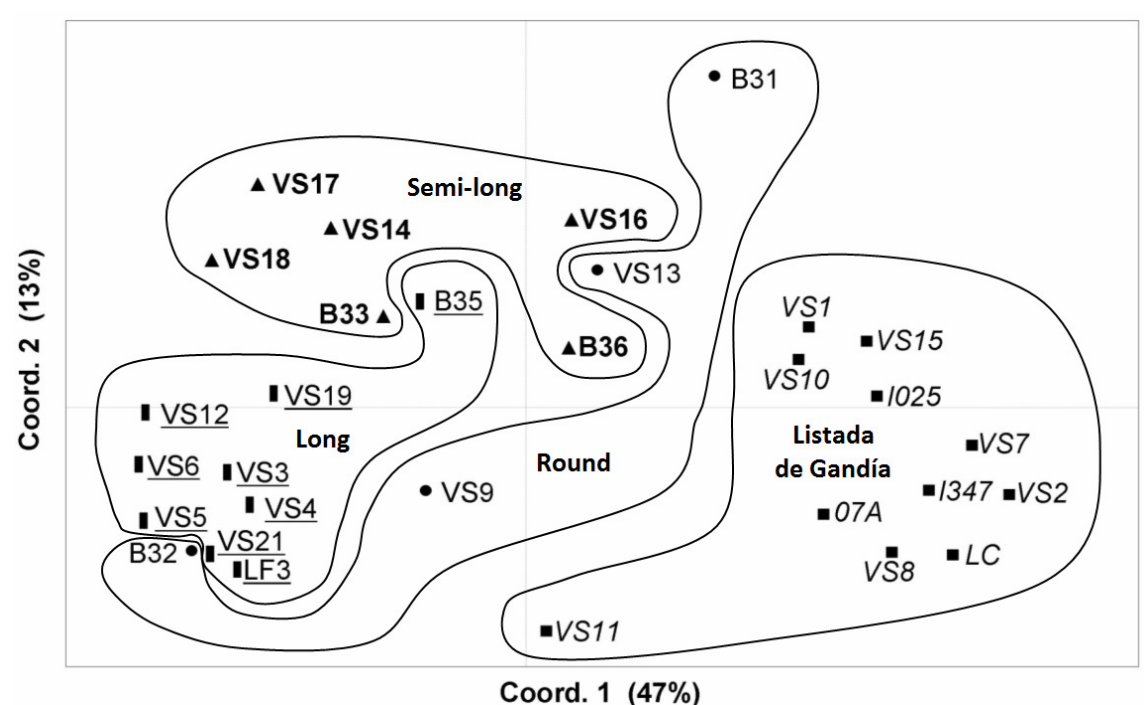

Fig. 2. Relationships between the 30 eggplant accessions based on 15 polymorphic SSRs according to the first and second principal coordinates obtained from a principal coordinates analysis (PCoA) (47\% and 13\% of the total variation accounted by the first and second coordinates, respectively). The different groups of accessions are represented by different symbols and font types: Round ( $\bullet$ and normal font); Listada de Gandía (• and italics font); Semi-long ( $\boldsymbol{\Delta}$ and bold font); long (\ and underlined font)

the PCoA graph, with either low positive or negative values for the first coordinate and positive values for the second coordinate. Conversely to the other cultivar groups, the four Round accessions are scattered in different parts of the PCoA graph, with two accessions presenting positive values for both the first and second coordinates and situated close to Semi-Long accessions, and two accessions with negative values for both coordinates, with one accession (B32) close to Long accessions and the other (VS9) close to the odd VS11 Listada de Gandía accession (Fig. 2).

\section{Discussion}

Genomic SSRs that previously proved to be highly polymorphic in eggplant (Vilanova et al., 2012) have been found to be of great value for evaluating the genetic diversity and relationships in a collection of eggplants from different cultivar groups. The screening of this collection has revealed a high degree of polymorphism for the SSR markers tested, confirming that the Mediterranean region is a secondary center of diversity for eggplant (Cericola et al., 2013; Hurtado et al., 2012; Prohens et al., 2005). Muñoz-Falcón et al. (2011) have shown that in eggplant genomic SSR markers are more polymorphic than EST-SSRs. Our results seem to confirm these results and that the genomic SSRs developed from an enriched genomic library by Vilanova $e t$ al. (2012) are particularly useful for the study of relationships in germplasm collections.

The same SSRs used by us were tested by Vilanova et al. (2012) in a collection of $22 \mathrm{~S}$. melongena from different origins, including Occidental and Oriental types of eggplant. For the 15 polymorphic loci used in our study these authors found an average number of alleles per locus (6.47) higher than ours (4.33). Hurtado et al. (2012) in a study of 52 accessions from China, Spain, and Sri Lanka shared seven of the SSR markers that have been polymorphic in our study and also found a higher average number of alleles per locus (8.86) than we found for these seven SSR markers in our study (4.43). Also, Cericola et al. (2013) in a wide study of 238 eggplant materials from different origins shared four SSRs with our study. For these four SSRs, Cericola et al. (2013) found on average 7 alleles/locus, while these same alleles in our collection presented a mean of 5.5 alleles/locus.

The higher diversity found by Vilanova et al. (2012), Hurtado et al. (2012), and Cericola et al. (2013) probably is a consequence of the fact that our collection comes from a single geographic area (Region of Valencia, in the Mediterranean coast of Spain). In fact, when considering only the 14 Spanish accessions used in the Hurtado et al. (2012) study the number of alleles per locus (3.86) is similar to ours (4.43). Amazingly, for the CSM32 loci, which has been monomorphic in our collection, Hurtado et al. (2012) and Vilanova et al. (2012) found 12 and 8 alleles, respectively, indicating that selection or genetic drift in the materials of the collection we have evaluated have led to fixation of one specific allele.

SSR loci are highly informative when they present a great number of alleles $\left(N_{a}\right)$, and have low values for the predominant allele frequency $\left(f_{p}\right)$, i.e., with $f_{p}$ values close to the theoretical minimum of $f_{p}=1 / N_{a}$ (Botstein et al., 1980; Powell et al., 1996). In our case, some markers have presented a high number of alleles and presented relatively low values for the predominant allele $\left(f_{p}\right)$, resulting in high values for the number of effective alleles $\left(N_{e}\right)$ polymorphic information content $(P I C)$, and expected heterozygosity $\left(H_{e}\right)$ confirming that highly relevant information on the diversity and relationships of eggplant can be obtained with a relatively low number of genomic SSR markers (Hurtado et al., 2012; Muñoz-Falcón et al., 2009, 2011).

The low values of observed heterozigosity $\left(H_{o}\right)$ were 
expected as eggplant is fundamentally autogamous (Pessarakli and Dris, 2004), and the materials used are nonhybrid. In this respect, Muñoz-Falcón (2009) also found very low values for $H_{o}$ in eggplant landraces $\left(H_{o}<0.03\right)$, but substantially higher values $\left(H_{0}=0.38\right)$ for commercial F1 hybrids. Cericola et al. (2013) also found that most eggplant landraces used in their study had low heterozygosity values, and only 38 out of 238 materials had $H_{o}>0.10$. The high level of homozygosity in eggplant landraces shows that pure lines can easily be derived by individual selection from these materials.

The multivariate analysis with SSR markers shows that, as already found by Prohens et al. (2005) and Tümbilen et al. (2011) with AFLP markers, and by Cericola et al. (2013) that considerable genetic diversity exists within each of the cultivar groups studied, which were mostly distinguished by the fruit shape. Also, Muñoz-Falcón et al. (2011) using SSR markers also found that one of the groups studied here (Listada de Gandía) was genetically diverse.

The existence of intra-varietal group genetic diversity has important implications for selection and breeding as it indicates that important genetic advances can be obtained with intra-cultivar group selection, and also that hybrids heterotic for yield may be obtained when crossing genetically different accessions of the same cultivar group (Rodríguez-Burruezo et al., 2008).

Here we have found that a certain degree of genetic differentiation exists among the four cultivar groups. This is in agreement with previous reports (Cericola et al., 2013; Prohens et al., 2005; Tümbilen et al., 2011), in which cultivar groups were found to present a moderate degree of differentiation. However, the Round group accessions were intermingled in the multivariate analyses with accessions of other groups indicating that this cultivar group is genetically highly variable. Wild relatives of eggplant have round, ovoid, or obovoid fruit shape (Knapp et al., 2013), indicating that the fruit shape characteristic of the Round cultivar group (Hurtado et al., 2013) is an ancestral trait probably present in the first domesticated eggplants. As occurred in tomato (Brewer et al., 2007), artificial selection of mutations affecting fruit shape has led to other fruit shapes, like those characteristic of the Listada de Gandía, Semi-Long and Long types, which may have undergone genetic bottlenecks resulting in a lower diversity and higher degree of genetic differentiation. However, further studies should be undertaken to confirm this hypothesis.

In our study, the Long and Listada de Gandía groups are clearly differentiated at the genetic level. In this respect, Muñoz-Falcón et al. (2011) and Prohens et al. (2005) found that the Listada de Gandía cultivar group was genetically clearly differentiated from the rest of eggplant materials of other types. In our study, only one of the Listada de Gandía accessions used (VS11) seems to be genetically closer to one Round accession (VS9) that to other Listada de Gandía materials. This accession is characterized by an odd shape for the Listada de Gandía type, as it is ovoid instead of having the normal obovoid shape characteristic of the Listada de Gandía materials (Hurtado et al., 2013) and may have been derived from introgression of the striped trait characteristic of Listada de Gandía into a different genetic background.

\section{Conclusions}

A reduced number of selected genomic SSR markers have allowed detecting considerable genetic variation in a collection of eggplants including different cultivar types. These markers have also been useful for studying relationships among four cultivar groups differentiated by fruit shape, showing that they are highly homozygous, have considerable intra-varietal group diversity, and present a certain degree of genetic differentiation. In particular the Listada de Gandía and Long varietal groups are clearly differentiated from each other. This information is of interest for the genetic improvement and conservation of genetic resources of eggplant.

\section{Acknowledgements}

This research has been partially funded by Ministerio de Economía y Competitividad and FEDER (grant AGL201234213) and by Universitat Politècnica de Valencia (grants SP20120681 and PAID-06-11 Nr. 2082).

\section{References}

Botstein D, White RI, Skolnich M, Davis RW (1980). Construction of a genetic linkage map in man using restriction fragment polymorphism. Amer J Human Genet 32:324-331.

Barchi L, Lanteri S, Portis E, Valè G; Volante A; Pulcini L, Ciriaci T, Acciarri N, Barbierato V, Toppino L, Rotino GL (2012). A RAD tag derived marker based eggplant linkage map and the location of QTLs determining anthocyanin pigmentation. PLoS ONE 7:43740.

Brewer MT, Moyseenko JB, Monforte AJ, van der Knaap E (2007). Morphological variation in tomato: A comprehensive study of quantitative trait loci controlling fruit shape and development. J Exp Bot 58:1339-1349.

Cericola F, Portis E, Toppino L, Barchi L, Acciarri N, Ciriaci T, Sala T, Rotino GL, Lanteri S (2013). The population structure and diversity of eggplant from Asia and the Mediterranean basin. PLoS ONE 8:73702.

Dice LR (1945). Measures of the amount of ecologic association between species. Ecology 26:297-302.

Doyle JJ, Doyle JL (1987). A rapid DNA isolation procedure for small quantities of fresh leaf tissue. Phytochem Bull 19:11-15.

Hurtado M, Vilanova S, Plazas M, Gramazio P, Fonseka HH, Fonseka R, Prohens J (2012). Diversity and relationships of eggplants from three geographically distant centers of diversity. PLoS ONE 7:41748.

Hurtado M, Vilanova S, Plazas M, Gramazio P, Herraiz FJ, Andújar I, Prohens J (2013). Phenomics of fruit shape in eggplant (Solanum melongena L.) using Tomato Analyzer software. Sci Hort 164:625-632.

Knapp S, Vorontsova MS, Prohens J (2013). Wild relatives of eggplant (Solanum melongena L.: Solanaceae): New understanding of species names in a complex group. PLoS ONE 8:57039.

Lebeau A, Gouy M, Daunay MC, Wicker E, Chiroleu F, Prior P, 
Frary A, Dintinger J (2013). Genetic mapping of a major dominant gene for resistance to Ralstonia solanacearum in eggplant. Theor Appl Genet 126:143-158.

Liu K, Muse S (2005). PowerMarker: an integrated analysis environment for genetic marker analysis. Bioinformatics 21:2128-2129.

Meyer RS, Karol KG, Little DP, Nee MH, Litt A (2012). Phylogeographic relationships among Asian eggplants and new perspectives on eggplant domestication. Mol Phylogenet Evol 63:685-701.

Muñoz-Falcón JE, Prohens J, Vilanova S, Nuez F (2009a). Diversity in commercial varieties and landraces of black eggplants and implications for broadening the breeders' gene pool. Ann Appl Biol 154:453-465.

Muñoz-Falcón JE, Prohens J, Vilanova S, Ribas F, Castro A, Nuez $\mathrm{F}$ (2009b). Distinguishing a protected geographical indication vegetable (Almagro eggplant) from closely related varieties using morphological traits and molecular markers. J Sci Food Agric 89:320-328.

Muñoz-Falcón JE, Vilanova S, Plazas M, Prohens J (2011). Diversity, relationships, and genetic fingerprinting of the Listada de Gandia eggplant landrace using genomic SSRs and EST-SSRs. Sci Hort 129:238-246.

Nei M, Li W.H. (1979). Mathematical modelfor studying genetic variation in terms of restriction endonucleases. Proc Natl Acad Sci USA 76:5269-5273.

Page RDM (1996). TreeView: An application to display phylogenetic trees on personal computers. Comp Appl Biosci 12:357-358.

Peakall R, Smouse PE (2006). GenAlEx 6.5: Genetic analysis in Excel. Population genetic software for teaching and research an update. Bioinformatics 28:2537-2539.

Pessarakli MM, Dris R (2004). Pollination and breeding of eggplant. J Food Agric Environ 2:218-219.

Plazas M, López-Gresa MP, Vilanova S, Torres C, Hurtado M, Gramazio P, Andújar I, Herráiz FJ, Bellés JM, Prohens J (2013). Diversity and relationships for key traits for functional and apparent quality in a collection of eggplant: Fruit phenolics content, antioxidant activity, polyphenol oxidase activity, and browning. J Agric Food Chem 61:8871-8879.
Powell W, Machray GC, Provan J (1996). Polymorphism revealed by simple sequence repeats. Trends Plant Sci 1:215-222.

Prohens J, Blanca JM, Nuez F (2005). Morphological and molecular variation in a collection of eggplants from a secondary center of diversity: Implications for conservation and breeding. J Amer Soc Hort Sci 130:54-63.

Rodríguez-Burruezo A, Prohens J, Nuez F (2008). Performance of hybrids between local varieties of eggplant (Solanum melongena) and its relation to the mean of parents and to morphological and genetic distances among parents. Eur J Hort Sci 73:76-83.

Sambrook J, Fritsch EF, Maniatis T (1989). Molecular cloning: A laboratory manual, $2^{\text {nd }}$ ed. Cold Spring Harbor Laboratory Press, Cold Spring Harbor, NY, USA, p. 1626.

Schuelke M (2000). An economic method for the fluorescent labeling of PCR fragments. Nature Biotechnol 18:233-234.

Sunseri F, Sciancalepore A, Martelli G, Acciarri N, Rotino GL, Valentino D, Tamietti G (2003). Development of RAPDAFLP map of eggplant and improvement of tolerance to Verticillium wilt. Acta Hort 625:107-115.

Tümbilen Y, Frary A, Mutlu S, Doganlar S (2011). Genetic diversity in Turkish eggplant (Solanum melongena) varieties as determined by morphological and molecular analyses. Intl Res J Biotechnol 2:16-25.

Vilanova S, Blasco M, Hurtado M, Muñoz-Falcón JE, Prohens J, Nuez F (2010). Development of a linkage map of eggplant based on a $S$. incanum $\mathrm{x} S$. melongena backcross generation, $\mathrm{p}$. 435-439. In: Prohens J, Rodríguez-Burruezo A (Eds.). Advances in genetics and breeding of Capsicum and eggplant. Ed. Universitat Politècnica de València, Valencia, Spain.

Vilanova S, Manzur JP, Prohens J (2012). Development and characterization of genomic simple sequence repeat markers in eggplant and their application to the study of diversity and relationships in a collection of different cultivar types and origins. Mol Breed 30:647-660. 